\title{
A Study of Depressive Features and Perceived Social Support in patients with Miscarriage
}

\author{
Megha Ashok Maghade ${ }^{1}$, Deepika Abhainath Singh ${ }^{2}$, Abhijeet Dhawalram Faye ${ }^{3}$, \\ Sushil Gawande ${ }^{4}$, Rahul Tadke ${ }^{5}$, Sudhir H. Bhave ${ }^{6}$, Vivek C. Kirpekar ${ }^{7}$ \\ ${ }^{1}$ Junior Resident \\ ${ }^{2}$ Senior Resident \\ ${ }^{3}$ Assistant Professor \\ ${ }^{4}$ Associate Professor \\ ${ }^{5}$ Associate Professor \\ ${ }^{6}$ Professor \\ ${ }^{7}$ Professor \& Head, \\ Department of Psychiatry, NKP Salve Institute of Medical Sciences and Lata Mangeshkar Hospital, \\ Nagpur.
}

Corresponding author: Megha Ashok Maghade

Email-megha.maghade@gmail.com

\begin{abstract}
Background: In developing world, the number of women undergoing miscarriage has increased. Women facing miscarriage are susceptible to develop depression and the risk is more if the perceived social support is low or not adequate. This study was conducted to assess the presence of depressive features and perceived social support and to correlate between the two entities in patients with miscarriage.

Methods: This was a cross-sectional, single interview study conducted in 100 consecutive patients with miscarriage in current pregnancy admitted in obstetrics and gynecology ward of a tertiary care center. After ethics committee approval and written informed consent, each patient was individually interviewed using a semi structured proforma. To assess depressive features, Patient Health Questionnaire-9 (PHQ-9) and to evaluate perceived social support- Multidimensional Scale for Perceived Social Support (MSPSS) were administered. Data was analyzed statistically.

Results: The mean age of the participant was 28.5 years (3.9), all of them were married, majority of them being housewives, with primary/secondary level of education and from rural area. On assessment with PHQ9, the prevalence of depression was $32 \%$. Among them $17 \%$ had mild depression, $12 \%$ had moderate depression, and 3\% had severe depression. Women with advancing age, lower education level, unemployment, previous miscarriage, miscarriage following treatment for infertility had significant depression. The perceived social support in the form of family and friends was significantly less in depressed patients.

Conclusion: Miscarriage is a significant stressful event in a women's life. These women should be evaluated for depressive symptoms and carers should be psycho-educated regarding need of social support following miscarriage. Early diagnosis and management of depression will help in reducing further morbidity and will improve the quality of life of these patients.
\end{abstract}

Keywords: Miscarriage, depression, perceived social support.

(Paper received $-24^{\text {th }}$ April 2018, Peer review completed $-29^{\text {th }}$ May 2018)

(Accepted $-30^{\text {th }}$ May 2018) 


\section{INTRODUCTION}

Miscarriage also called Spontaneous abortion is defined as a clinically recognized pregnancy loss before the 20th week of gestation [1-2]. The World Health Organization (WHO) defines it as expulsion or extraction of an embryo or foetus weighing $500 \mathrm{~g}$ or less [3]. Between $14 \%$ and $20 \%$ of clinically recognized pregnancies end in miscarriage [4]. Miscarriage being the most common form of reproductive loss, In India, it is considered among the major causes of maternal mortality and morbidity [5]. Depression is commonest cause of disability worldwide which affects an individual's quality of life. World Health Organization (WHO), predicts major depressive disorder is to be a major reason for disability in the world by 2030 . The cardinal symptoms of major depressive disorder include depressed mood, anhedonia, easy fatigability, difficulty in concentrating, disrupted sleep, appetite and cognition and tendency to attempt suicide [6].

Miscarriage is a distressing life event. Anxiety, Grief and depression commonly follows miscarriage, depressive features last for longer period following miscarriage. Studies have shown that Women facing spontaneous pregnancy loss are very commonly depressed. They have a sense of loss, sense of loneliness, sadness and guilt feelings. Especially women facing recurrent pregnancy loss are more severely depressed [7-9]. Depression is more prevalent in women with reproductive age group than general population and is associated with social and occupational impairment [10].

Social support is physical, mental, emotional care which the family member, relative, friend provide during the stressful events. Social support is needed to deal effectively with the stressful event of miscarriage. Availability of effective coping strategies and its use during the periods of stress helps to modify the psychological functioning of the individual. Perceived support is Subjective evaluation of the received help [11-12]. Studies have shown that women's personal characteristics (level of self-esteem or personal control), relationship context (partner support and conflict or partner attributions for the pregnancy), and other contextual factors, (pregnancy intention or encountering picketers in front of the abortion clinic) influence coping strategies, which in turn influence post-miscarriage psychological health. Social support is important in the emotional adaptation to miscarriage [13-14]. Literature have shown lack of support from partner, family and friends to be a risk factor for psychological morbidity following miscarriage and other traumatic events [15-16].

Various studies have shown that the patients with miscarriage are likely to suffer from depression, evaluation of depressive features among this high-risk group can help in early intervention that will help in alleviating the depressive symptoms. Also understanding the importance of psychosocial support during most stressful period of miscarriage can help in evaluating it as a risk factor for depression. On the other hand, if psychosocial support is good it acts as a positive factor in overcoming stress. Thus, this study was conducted to assess the presence of depressive symptoms and psychosocial support and their correlations with various socio-demographic factors among patients with miscarriage.

\section{METHODOLOGY}

This was a cross-sectional, non-randomized, single interview study carried out in obstetric and gynaecological unit of a tertiary care hospital. Study was conducted after taking permission from institutional ethics committee 100 consecutive patients with abortion in current pregnancy (excluding those who had induced abortion) and willing to be a part of study were included after obtaining written informed consent. Each patient was individually interviewed using a semi-structured proforma prepared for the study which included sociodemographic profile; clinical profile including pregnancy details; psychiatric profile; and gynaecological diagnosis. To assess depressive features patient health questionnaire [17] (PHQ-9) was administered. The scale consists of 9 items used for screening, diagnosing, monitoring and measuring severity of depression. Each item is scored on a scale of 0 (not at all) to 3 (nearly every day), with the total score range of $0-27$. Scores of 5, 10, 15 and 20 represents mild, moderate, moderately severe and severe depression. To assess the perceived social support multidimensional scale for perceived social support [18] (MSPSS) was administered. The scale measures perception of support from 3 sources -family, friends and significant other. The scale consists of total of 12 items with 4 items for each of the three sub-scale (i.e. family subscale, friend subscale and significant other subscale) cut off scores based on mean scale score of 1 
to 2.9 -- low support, 3 to 5 -- moderate support, and 5.1 to 7 -- high support Interviews were conducted 4872 hours after abortion and each interview required about 30 minutes. Data thus collected was tabulated and analyzed using non-parametric tests under guidance of statistician to draw the conclusion.

\section{RESULTS}

\section{Prevalence of Depression}

The study population included 100 patients with spontaneous abortion. Of these 100 participants, 32 patients scored $\geq 5$ on PHQ9 and hence diagnosed as having depression. Those scoring between 5 and 9 were diagnosed as having mild depression, i.e., $17 \%$ patients, those scoring between 10 and 19 were diagnosed with moderate depression, i.e., $12 \%$ patients and those scoring between 20 and 27 were diagnosed with severe depression, i.e., $3 \%$ patients.

Prevalence of depression in our study was $32 \%$ i.e. almost twice the general population. $53.12 \%(n=17)$ of patients who had depression, had mild depression and $46.87 \%(n=15)$ of patients had severe depression based on their scores on PHQ9.

\section{Sociodemographic Profile}

More than half of the patients, i.e., 55 of 100 patients in the study population were $\leq 30$ years of age and 45 patients were $>30$-year-old. Of these 55 patients, 12 were depressed and 43 were nondepressed. Of the 45 patients of above 30 years age group 20 were depressed and 25 were nondepressed. Prevalence of depression was significantly more in women aged 30 yrs. and above, on administering Fisher's exact test with $p=$ 0.0189. All the participants in the study were married. 57 of 100 patients in our study were living in rural area while 43 patients were from urban background. About $53.12 \%$ of the depressed patients resided in rural areas and $46.87 \%$ patients resided in urban areas however this difference in residential background was not statistically significant with $\mathrm{p}=0.5913$.

In the present study, 75 patients were educated till primary/secondary level and 25 patients were educated till college/university level. Nearly $6.75 \%$ of depressed patients had primary/secondary level and $31.25 \%$ of patients had college/university level of education. On administering Fisher's exact test, no statistically significant difference between two groups was found $(p=0.322)$

Unemployment may lead to depression, thus we compared working patients (i.e. patients doing jobs and getting salary) with those who were not working (housewives). 40 out of 100 patients were working, whereas 60 patients were not working. Nearly $75 \%$ of patients who were not working were depressed as compared to $25 \%$ of patients who were working, and this difference was statistically significant according to Fisher's exact test with $p=0.0251$. This shows depression to be seen more often in patients with unemployment, which is one of the risk factors associated with depression. [Table 1]

\section{Perceived Social Support and Depression}

The perceived social support between depressed and non-depressed patient was compared using t-test. In the study, for MSPSS depressed patients had less perceived social support from family members and friends as compared to non-depressed patients and this difference was statistically significant with $p<0.05$. However, with respect to support from significant others, no statistically significant difference was found [Table 2].

\section{Correlation of Depression with Perceived Social Support}

In this study, Spearman's correlation was used to assess the correlation between the severity of depression (based on PHQ 9 score) and perceived social support. It was found that as the level of depression increased the perceived social support decreased. Hence, severity of depression was negatively correlated with perceived social support in any form - family, friend or significant others. 
Table 1 - Socio-demographic Profile

\begin{tabular}{|c|c|c|c|}
\hline Socio demographic profile & $\begin{array}{l}\text { Non-depressed } \\
(\mathrm{n}=68), \mathrm{n}(\%)\end{array}$ & $\begin{array}{l}\text { Depressed } \\
(\mathrm{n}=32), \mathrm{n}(\%)\end{array}$ & $\begin{array}{l}\text { Statistical } \\
\text { Test }\end{array}$ \\
\hline $\begin{array}{l}\text { Age (Years) } \\
\leq 30 \\
>30\end{array}$ & $\begin{array}{l}43(63.23) \\
25(36.76)\end{array}$ & $\begin{array}{l}12(37.5) \\
20(62.5)\end{array}$ & $\begin{array}{l}p=0.01 \\
\text { Significant }\end{array}$ \\
\hline $\begin{array}{l}\text { Education } \\
\text { Primary / secondary } \\
\text { College/university }\end{array}$ & $\begin{array}{l}53(77.94) \\
15(22.05)\end{array}$ & $\begin{array}{l}22(68.75) \\
10(31.25)\end{array}$ & $\begin{array}{l}\mathrm{p}=0.32 \\
\text { not significant }\end{array}$ \\
\hline $\begin{array}{l}\text { Occupation } \\
\text { Employed } \\
\text { Unemployed }\end{array}$ & $\begin{array}{l}32(47.05) \\
36(52.94)\end{array}$ & $\begin{array}{l}8(25) \\
24(75)\end{array}$ & $\begin{array}{l}\mathrm{p}=0.025 \\
\text { Significant }\end{array}$ \\
\hline $\begin{array}{l}\text { Residence } \\
\text { Rural } \\
\text { Urban }\end{array}$ & $\begin{array}{l}40(58.8) \\
28(41.1)\end{array}$ & $\begin{array}{l}17(53.1) \\
15(46.87)\end{array}$ & $\begin{array}{l}p=0.591 \\
\text { not significant }\end{array}$ \\
\hline $\begin{array}{l}\text { Previous miscarriage } \\
\text { Present } \\
\text { Absent }\end{array}$ & $\begin{array}{l}19 \\
49\end{array}$ & $\begin{array}{l}16 \\
16\end{array}$ & $\begin{array}{l}\mathrm{p}=0.03 \\
\text { significant }\end{array}$ \\
\hline $\begin{array}{l}\text { Treatment for infertility } \\
\text { Treatment taken } \\
\text { Treatment not taken }\end{array}$ & $\begin{array}{c}2 \\
65\end{array}$ & $\begin{array}{r}6 \\
27\end{array}$ & $\begin{array}{l}0.01 \\
\text { Significant }\end{array}$ \\
\hline
\end{tabular}

Table 2 - Perceived social support and depression

\begin{tabular}{|l|l|l|l|}
\hline $\begin{array}{l}\text { Perceived social } \\
\text { support }\end{array}$ & $\begin{array}{l}\text { Non-depressed (n=68) } \\
\text { Mean (SD) }\end{array}$ & $\begin{array}{l}\text { Depressed(n=32) } \\
\text { Mean (SD) }\end{array}$ & Statistical test \\
\hline MSPSS family & $20.9(7.4)$ & $16.65(7.2)$ & $\mathrm{p}=<0.01$ significant \\
\hline MSPSS friend & $22.2(6)$ & $18.4(4.8)$ & $\mathrm{p}=<0.01$ significant \\
\hline $\begin{array}{l}\text { MSPSS } \\
\text { significant other }\end{array}$ & $16.77(4.9)$ & $15.25(5.4)$ & $\begin{array}{l}\mathrm{p}=0.1 \\
\text { not significant }\end{array}$ \\
\hline $\begin{array}{l}\text { Spearman's } \\
\text { correlation }\end{array}$ & PHQ9 Depression Score & & Significance \\
\hline MSPSS family & -0.21 & $\begin{array}{l}0.03 \\
\text { not significant }\end{array}$ \\
\hline MSPSS friend & -0.28 & $\begin{array}{l}<0.01 \\
\text { significant }\end{array}$ \\
\hline $\begin{array}{l}\text { MSPSS } \\
\text { significant other }\end{array}$ & -0.19 & $\begin{array}{l}0.04 \\
\text { not significant }\end{array}$ \\
\hline $\begin{array}{l}\text { MSPSS: Multidimensional Scale of Perceived Social Support, } \\
\text { PHQ-9: Patient health Questionnaire, SD: Standard deviation }\end{array}$ & \\
\hline
\end{tabular}

\section{DISCUSSION}

It has been seen in number of studies that women with normal pregnancy can have significant psychiatric morbidity [19-21]. Therefore women who have had miscarriages are at increased risk of psychological distress. 
In our study, $32 \%$ women secured high score on the scale used for assessing depressive symptoms, therefore prevalence of depression was found to be high. The reason for the high prevalence could be because the patients were interviewed immediately (i.e. 24-48 hrs.) following abortion wherein the chances of patients being depressed were high, also Depression was assessed with the help of PHQ9, in which mild depressive symptoms are also identified. In Western populations the rate of depression after spontaneous abortion is reported around $20 \%$ while in Asian population prevalence reported was $12 \%$ and $10 \%$ after 6 weeks \& 3 months following abortion [22-24]. In a study done by Lok IH et al, shows a high prevalence of (26.8\%) depressive symptoms immediately after abortion [25].

From sociodemographic profile, it was seen that majority of the depressed patients were of the age 30 years and above. Similar finding was seen in the study done by Kulathilaka and others [26]. miscarriage faced during advancing age is significantly associated with an increased risk of depression. Pregnancy in late reproductive age is usually considered high risk and precious pregnancy and thus reproductive loss in this age is perceived as a sad and traumatic life event which may be a reason for depression in miscarrying women.

With respect to the residential background, in our study, women from rural background were found to be more depressed than those from urban background although this difference was not statistically significant [27]. In another study, high prevalence of depressive symptoms was seen in women from rural background. As shown in Table 1, depression was more prevalent in patient educated up to primary /secondary level. Though this difference was not statistically significant. According to a study, a low level of education was directly associated with depression in the miscarrying women. The well-educated women have better coping and hence can easily adjust with the situation as compared to those who are less educated. And therefore, are at a lesser risk for depression [26].

In a present study, there was a high prevalence of depression among unemployed women as compared to women who were working. Studies done have reported a high prevalence of depression among the unemployed women [28-29]. Most of the Unemployed women (mostly housewives) who are dependent on their partner for financial support were at higher risk for depression than those who were self-dependent. Lower income and financial dependency on others for fulfilling the financial needs of a person produces depressive symptoms.

In our study depressive symptoms were found to be more prevalent in women with history of previous miscarriage than those without such history and this difference was statistically significant $(p=0.03)$. A study done by Kolte and others [30] showed depression to be more prevalent in miscarrying women who faced prior pregnancy loss. Mayumi Sugiura-Ogasawara [31] in her study concluded that preconception depressive state may influence the risk of miscarriage in patients who had previous miscarriage. Repeated pregnancy loss may lead to psychological distress. Women after spontaneous foetal loss are stressed out and feel lonely. Lack of psychological care following miscarriage and Chronic stress might cause depression.

In current study, women who conceived after taking treatment for infertility and had spontaneous abortion were found to be more depressed (secured much higher scores on PHQ9 scale) than those without such history and this difference was statistically significant $(p=0.01)$ [32].

In developing countries, women's ability to reproduce is of utmost importance which helps her to achieve the desired social role. And when this ability is compromised, probable psychological distress often arise. In certain communities, women are often blamed for inability to conceive irrespective of the cause of infertility which also affects her mental state. When such women conceive with treatment and face spontaneous abortion later, they are more prone for ill mental health with feeling of guilt, future worries, fear, and frustration, all of which can have a cumulative effect in development of depressive state.

Thus, it was seen that predisposing factors for developing depression in patients with miscarriage were an age group of above 30 years, lower levels education, and unemployment, previous abortion, and abortion following treatment for infertility. In this study, the perceived social support from family members and friends, was significantly less in depressed patient group as compared to non-depressed group. In addition, it was found that severity of depression was negatively correlated with perceived social support in any form - family, friends or significant others. 
Previous studies have mentioned the importance of social support in adaptation to miscarriage Poor relations with husband, family members, Lack of care and emotional support from friends and neighbours may influence women's perception of social support. A study by G C Forrest concluded higher incidence of depressive symptoms like tearfulness, sadness, lethargy, insomnia, and physical manifestations of anxiety, such as palpitations, guilt, and irritability in unsupported group of women with perinatal loss in early pregnancy (within six months) attributed to social isolation and lack of intimacy with partner. Findings from a study done by Swanson [33] confirm that women those who attribute high personal significance to miscarriage, lack social support, have lower emotional strength are at risk for increased depressive symptoms after miscarriage. Results of the study by Convay [34] stated emotional response following miscarriage appears to be similar to the process of bereavement and social support from partners, relatives and friends helps women to adapt to the event of miscarriage.

Our study findings suggest that a sizable proportion of women after spontaneous abortion had depressive symptoms. Although none of the participants from our study fulfilled DSM-5 criteria for major depressive disorder and the group of women who experienced depression, requires medical attention and social support.

\section{CONCLUSION}

In conclusion, depressive symptoms were present in $32 \%$ of women in our sample population following miscarriage and factors that seem to have a negative impact on women's psychological response to miscarriage includes advancing age, lower education level, unemployment, previous abortion, abortion following treatment for infertility, lack of support from partner, family and friends. This study finding points out the importance of screening these women for depression after a miscarriage. Although with universal screening, earlier pick up of these women may reduce the subsequent well documented effects of depression and primarily offer better universal care after a miscarriage. Therefore, clinicians need assistance in identifying which women are at greatest risk for post abortion depression. This study's results can be immediately useful in helping clinicians identify such women in particular with those at increased risk. Family interventions will also be needed to improve the social support required by the patients.

\section{Limitations}

This study was conducted at a tertiary hospital, which may not be representative of the general population. In addition, this is a cross-sectional study and the sample size was small.

\section{REFERENCES}

1. Regan L, Rai R. Epidemiology and the medical causes of miscarriage. Best Pract Res Clin Obs Gynaec 2000;14(5):839-54.

2. Goddijn M, Leschot NJ. Genetic aspects of miscarriage. Best Pract Res Clin Obs Gynaec 2000;14(5):855-65.

3. World Health Organization. International statistical classification of diseases and related health problems. World Health Organization; 2004.

4. Blackmore ER, Côté-Arsenault D, Tang W, Glover V, Evans J, Golding J, O'Connor TG. Previous prenatal loss as a predictor of perinatal depression and anxiety. Br J Psychiatry 2011;198(5):373-8.

5. Sjöström S, Essén B, Gemzell-Danielsson K, Klingberg-Allvin M. Medical students are afraid to include abortion in their future practices: in-depth interviews in Maharastra, India. BMC Med Educ 2016;16(1):8.

6. Lépine JP, Briley M. The increasing burden of depression. Neuropsychiatr Dis Treat 2011;7(Suppl 1):3.

7. Kulathilaka S, Hanwella R, de Silva VA. Depressive disorder and grief following spontaneous abortion. BMC Psychiatry 2016;16(1):100.

8. Bellieni CV, Buonocore G. Abortion and subsequent mental health: Review of the literature. Psychiatr Clin Neurosci 2013;67(5):301-10.

9. Kolte AM, Olsen LR, Mikkelsen EM, Christiansen OB, Nielsen HS. Depression and emotional stress is highly prevalent among women with recurrent pregnancy loss. Hum Reprod 2015;30(4):777-82.

10. Kessler RC, Chiu WT, Demler O, Walters EE. Prevalence, severity, and comorbidity of 12-month DSM-IV disorders in the National Comorbidity Survey Replication. Arch Gen Psychiatry 2005;62(6):617-27.

11. Ogrodniczuk JS, Joyce AS, Piper WE. Changes in perceived social support after group therapy for complicated grief. J Nerv Ment Dis 2003;191(8):524-30. 
12. Bovier PA, Chamot E, Perneger TV. Perceived stress, internal resources, and social support as determinants of mental health among young adults. Qual Life Res 2004;13(1):161-70.

13. Steinberg JR, Tschann JM, Furgerson D, Harper CC. Psychosocial factors and pre-abortion psychological health: The significance of stigma. Soc Sci Med 2016;150:67-75.

14. Garel $\mathrm{M}$, Blondel $\mathrm{B}$, Lelong $\mathrm{N}$, Papin $\mathrm{C}$, Bonenfant $\mathrm{S}$, Kaminski M. Réactions dépressives après une fausse couche. Contraception Fertilité Sexualité 1992;20(1):75-81.

15. Forrest GC, Standish E, Baum JD. Support after perinatal death: a study of support and counselling after perinatal bereavement. Br Med J (Clin Res Ed) 1982;285(6353):1475-9.

16. Sarason IG, editor. Social support: Theory, research and applications. Springer Science \& Business Media; 2013.

17. Kroenke K, Spitzer RL, Williams JB. The PHQ-9: validity of a brief depression severity measure. J Gen Intern Med 2001;16:606-13.

18. Cheng ST, Chan AC. The multidimensional scale of perceived social support: Dimensionality and age and gender differences in adolescents. Pers Individ Dif 2004;37:1359- 69.

19. Kumar R, Robson KM. A prospective study of emotional disorders in childbearing women. Br J Psychiatry 1984;144(1):35-47.

20. Watson JP, Elliott SA, Rugg AJ, Brough DI. Psychiatric disorder in pregnancy and the first postnatal year. $\mathrm{Br}$ J Psychiatry 1984;144(5):453-62.

21. Cooper PJ, Campbell EA, Day A, Kennerley H, Bond A. Non-psychotic psychiatric disorder after childbirth: a prospective study of prevalence, incidence, course and nature. Br J Psychiatry 1988;152(6):799-806.

22. Bradshaw Z, Slade P. The effects of induced abortion on emotional experiences and relationships: a critical review of the literature. Clin Psychol Rev 2003;23(7):929-58.

23. 23.Lee DT, Wong CK, Cheung LP, Leung HC, Haines CJ, Chung TK. Psychiatric morbidity following miscarriage: a prevalence study of Chinese women in Hong Kong. J Affect Disord 1997;43(1):63-8.

24. Sham A, Yiu M, Ho W. Psychiatric morbidity following miscarriage in Hong Kong. Gen Hosp Psychiatry. 2010;32(3):284-93.

25. Lok IH, Yip AS, Lee DT, Sahota D, Chung TK. A 1-year longitudinal study of psychological morbidity after miscarriage. Fertil Steril 2010;93(6):1966-75.

26. Kulathilaka S, Hanwella R, de Silva VA. Depressive disorder and grief following spontaneous abortion. BMC Psychiatry 2016;16(1):100.

27. Villegas L, McKay K, Dennis CL, Ross LE. Postpartum depression among rural women from developed and developing countries: a systematic review. J Rural Health 2011;27(3):278-88.

28. Gjerdingen D, McGovern P, Attanasio L, Johnson PJ, Kozhimannil KB. Maternal depressive symptoms, employment, and social support. J Am Board Fam Med 2014;27(1):87-96.

29. Miyake Y, Tanaka K, Sasaki S, Hirota Y. Employment, income, and education and risk of postpartum depression: the Osaka Maternal and Child Health Study. J Affect Disord 2011;130(1):133-7.

30. Kolte AM, Olsen LR, Mikkelsen EM, Christiansen OB, Nielsen HS. Depression and emotional stress is highly prevalent among women with recurrent pregnancy loss. Hum Reprod 2015;30(4):777-82.

31. Sugiura-Ogasawara M, Furukawa TA, Nakano Y, Hori S, Aoki K, Kitamura T. Depression as a potential causal factor in subsequent miscarriage in recurrent spontaneous aborters. Hum Reprod 2002;17(10):2580-4.

32. Lok IH, Lee DT, Cheung LP, Chung WS, Lo WK, Haines CJ. Psychiatric morbidity amongst infertile Chinese women undergoing treatment with assisted reproductive technology and the impact of treatment failure. Gynec Obst Inv 2002;53(4):195-9.

33. Swanson KM. Predicting depressive symptoms after miscarriage: A path analysis based on the Lazarus paradigm. J Women's Health Gender Based Med 2000;9(2):191-206.

34. Conway K. Miscarriage experience and the role of support systems: a pilot study. Psychol Psychother Theory Res Pract 1995;68(3):259-67.

$* * * * * * * * * * * * * * * * * * * * * * * * * * * * * * * * * * * *$

\author{
Acknowledgements - Nil \\ Conflict of Interest - Nil \\ Funding - Nil
}

